\title{
Separation of Gold, Palladium and Platinum from Metallurgical Samples Using an Amberlite XAD-7 Resin Column Prior to Their Atomic Absorption Spectrometric Determinations
}

\author{
Latif ElCI, ${ }^{* \dagger}$ Mustafa SoylaK,** and Emel B. BUYUKSEKERCI** \\ *Pamukkale University, Faculty of Art and Science, Department of Chemistry, 20020-Kınıkl,, Denizli, Turkey \\ **Erciyes University, Faculty of Art and Science, Department of Chemistry, 38039, Kayseri, Turkey
}

\begin{abstract}
A simple and sensitive method for the separation and preconcentration of gold, palladium and platinum has been established prior to their atomic absorption spectrometric determinations. Analytes from $0.5 \mathrm{~mol} \mathrm{dm}^{-3} \mathrm{KI}$ in a $2 \mathrm{~mol} \mathrm{dm}^{-3}$ $\mathrm{HCl}$ solution were recovered using an Amberlite XAD-7 column as halogeno complexes. The effects of some analytical parameters, including reagent amounts, sample volume and flow rates, on the quantitative recoveries of gold, palladium and platinum were investigated. The influences of some diverse ions were also studied. The proposed method has been applied for the preconcentration and separation of analytes from pure copper and anodic slime samples with satisfactory results (recoveries $>95 \%$, relative standard deviations $<9.0 \%$, relative error $\leq 5 \%$ ).
\end{abstract}

(Received March 11, 2002; Accepted August 8, 2003)

It has been known for long time that gold, palladium and platinum are present in most ores, alloys and concentrates at very low values. The detection limits of an atomic absorption spectrometer are not low enough for their direct determinations in sample solutions. The determination of gold, palladium and platinum is also difficult because of the large concentrations of unwanted metals and/or salts, such as sodium, iron, nickel and copper. To minimize such problems, the analysis must incorporate preconcentration and separation steps to free these precious metals from the matrix components. In addition, high concentrations of matrix constituents, including the acids used for sample dissolution or digestion, may cause inaccuracies in a method, which is based on external calibration with dilute aqueous standards. For this purpose, several preconcentration and separation procedures for gold, palladium and platinum, such as solvent extraction, ${ }^{1-3}$ coprecipitation, ${ }^{4,5}$ ion-exchange ${ }^{6-8}$ and adsorption, ${ }^{9-11}$ have been suggested. Among these procedures, by far, the most popular procedure for analyte concentration and separation is solid-phase extraction. In general, the analyte from a relatively large volume of solution is selectively retained by a solid-phase material based on a variety of mechanisms, and then released into a relatively small volume of eluent. In solid-phase extraction procedures based on adsorption, complexes, chelates and ion associates, the analytes are retained on columns filled with XAD resins, ${ }^{12,13}$ polyurethane foams, ${ }^{14}$ activated carbon ${ }^{15-17}$ and silica gel ${ }^{18,19}$ etc . Amberlite XAD series in most studies in our working group have been successfully used. ${ }^{20-24}$

The great tendency of gold, palladium and platinum to form very stable complex makes it possible to use inorganic complexing agents and extraction for their preconcentration. After sample decomposition, gold, palladium and platinum usually come in the form of stable halogeno complexes. For

$\dagger$ To whom correspondence should be addressed.

E-mail: elci@pamukkale.edu.tr this reason, numerous procedures based on the use of halogeno complexes have been proposed for the preconcentration and separation of gold, palladium and platinum. ${ }^{7,25,26}$

In this paper, a procedure is described for the determination of gold, palladium and platinum at trace levels in various metallurgic materials, such as pure copper and anodic slime, by applying complexation with halogenide and solid-phase extraction with an Amberlite XAD-7 resin column in combination with atomic absorption spectrometry.

\section{Experimental}

\section{Instrument}

A Perkin-Elmer Model 3110 atomic absorption spectrometer equipped with an air-acetylene burner was used for the determination of gold, palladium and platinum. The instrumental parameters were those recommended by the manufacturer. A pH meter (Nel pH-900 Model with a glasselectrode) was employed for measuring the $\mathrm{pH}$ values in the aqueous phase.

\section{Reagents and standard solutions}

All reagents were of analytical grade unless otherwise specified. Double-distilled water was used throughout the experiments. Extrapure hydrochloric acid and nitric acid from Merck, Darmstadt were used to prepare the acid solutions and buffer solution used throughout this work and the digestion of samples. Potassium iodide was purchased from Merck, Darmstadt.

Aqueous test solutions containing $5 \mu \mathrm{g}$ of gold(III), $5 \mu \mathrm{g}$ of palladium(II) and $10 \mu \mathrm{g}$ of platinum(II) per $25 \mathrm{~mL}$ and their standard solutions used for the calibration were prepared by dilution of a $1000 \mathrm{mg} \mathrm{L}^{-1}$ stock solution (Aldrich) with $1 \mathrm{~mol}$ $\mathrm{dm}^{-3} \mathrm{HCl}$ for the each analyte. 


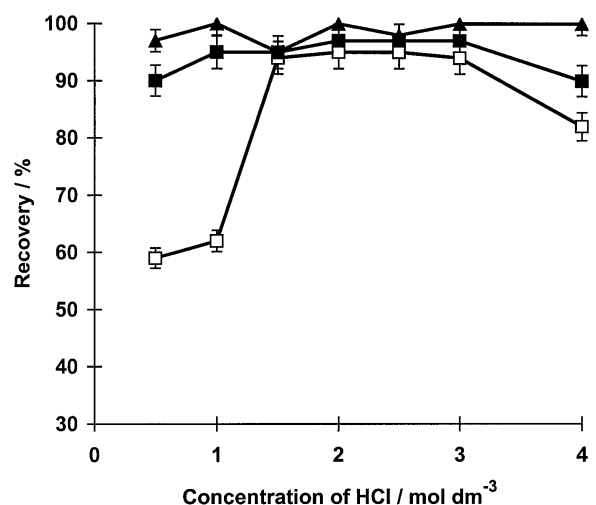

Fig. 1 Effect of the hydrochloric acid concentration on the recoveries of gold ( $\boldsymbol{\Lambda})$, palladium $(\boldsymbol{\square})$ and platinum $(\square)(n=4)$.

\section{Column preparation}

A $500 \mathrm{mg}$ sample of Amberlite XAD-7 (particle size, 0.3 - 0.9 $\mathrm{mm}$ ) resin suspended in water was slurry-packed in a glass column (10 mm i.d.) fitted with a porous disk filter and a glass stopcock. Amberlite XAD-7 resin, from Merck, Darmstadt was cleaned according to a procedure described elsewhere. ${ }^{21}$ After completing each experiment, the column was rinsed with a very large volume of the water and stored for the next use.

General procedure for the separation of gold, palladium and platinum

Aqueous test solutions containing $5 \mu \mathrm{g}$ of gold, $5 \mu \mathrm{g}$ of palladium and $10 \mu \mathrm{g}$ of platinum were prepared in $25 \mathrm{ml}$ of various matrices including $\mathrm{HCl}$ and $\mathrm{KI}$ at varying concentrations. The test solutions were gravitationally passed through a column at a flow rate of $5 \mathrm{ml} \mathrm{min}{ }^{-1}$. The retained analytes were eluted by $8-10 \mathrm{ml}$ of acetone at a flow rate of $1-$ $2 \mathrm{~mL} \mathrm{~min}{ }^{-1}$. The flow rates were controlled over the range of $1.0-25 \mathrm{~mL} \mathrm{~min}^{-1}$ by a stopcock of the column. The effluent was collected in a small glass beaker and carefully evaporated to $0.5-1 \mathrm{~mL}$ on a hot plate adjusted to $c a .30-40^{\circ} \mathrm{C}$. The residue was diluted to 2 or $5 \mathrm{~mL}$ using a $1 \mathrm{~mol} \mathrm{dm}^{-3} \mathrm{HCl}$ solution. $\mathrm{Au}, \mathrm{Pd}$ and $\mathrm{Pt}$ in the final solution were determined by using atomic absorption spectrometry.

\section{Procedure for metallurgical samples}

Metallurgical samples, anodic slime directly and pure copper after washing their surfaces, were dried at $110^{\circ} \mathrm{C}$ for $2 \mathrm{~h}$. A 50 $200 \mathrm{mg}$ amount of sample was decomposed with $5-10 \mathrm{~mL}$ of aqua regia and the solution was evaporated to dryness. This process was repeated twice. Ten milliliters of $2 \mathrm{~mol} \mathrm{dm}^{-3} \mathrm{HCl}$ were added to the residue. The suspension was filtered through blue band filter paper (Advantec Toyo 5A), and the insoluble part was washed with a solution containing $2 \mathrm{~mol} \mathrm{dm}^{-3} \mathrm{HCl}$ and $0.5 \mathrm{~mol} \mathrm{dm}^{-3} \mathrm{KI}$. The final solution was diluted to $25 \mathrm{ml}$ with a mixture solution of $2 \mathrm{~mol} \mathrm{dm}^{-3} \mathrm{HCl}$ and $0.5 \mathrm{~mol} \mathrm{dm}^{-3} \mathrm{KI}$. Then, the general procedure was applied to the final solutions.

\section{Results and Discussion}

\section{Effect of the $\mathrm{HCl}$ and $\mathrm{KI}$ concentrations}

Gold, palladium and platinum form stable complexes with chloro, bromo, iodo and thiocyanato ligands. ${ }^{27,28}$ Until now, these complexes have been used for the extraction of gold, palladium and platinum from an aqueous solution to an organic

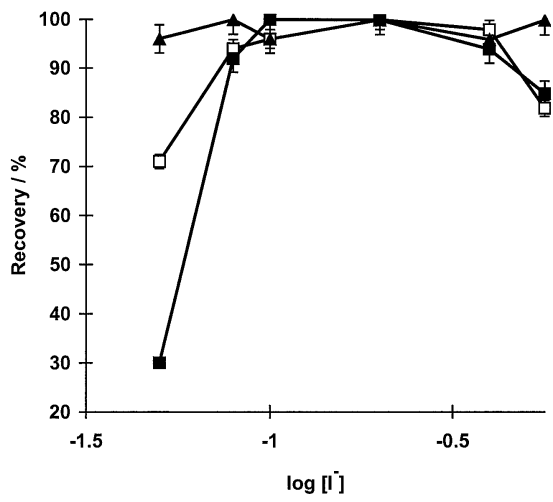

Fig. 2 Recoveries of gold ( $\mathbf{\Delta})$, palladium ( $\boldsymbol{\square}$ ) and platinum ( $\square$ ) from iodide solutions at various concentrations including $2 \mathrm{~mol} \mathrm{dm}^{-3}$ hydrochloric acid $(n=4)$.

phase. ${ }^{29-31}$ To adopt these solvent-extraction processes to solidphase extraction using Amberlite XAD-7 resin as a solid-phase material, the effect of the ligand concentrations on the recovery of gold, palladium and platinum was optimized.

The effect of a chloro ligand on the recoveries was examined using a test solution prepared with a $\mathrm{HCl}$ solution in varying concentrations. The results are depicted in Fig. 1. Gold was quantitatively recovered over a wide concentration range of $\mathrm{HCl}$ as $0.5-4 \mathrm{~mol} \mathrm{dm}^{-3}$. The quantitative recoveries of palladium were obtained in the range of $1-3 \mathrm{~mol} \mathrm{dm}^{-3} \mathrm{HCl}$. The recovery of platinum was nearly $90 \%$ in the range of $1.5-3 \mathrm{~mol} \mathrm{dm}^{-3}$ $\mathrm{HCl}$ concentration. Therefore, all subsequent studies were performed with $2 \mathrm{~mol} \mathrm{dm}^{-3} \mathrm{HCl}$.

To obtain a quantitative recovery for platinum, the effect of the iodide concentration on the recoveries of gold, palladium and platinum was also investigated using a test solution prepared with varying concentrations of iodide in $2 \mathrm{~mol} \mathrm{dm}^{-3}$ $\mathrm{HCl}$. The obtained results are shown in Fig. 2. Gold, palladium and platinum were retained together from a $0.5 \mathrm{~mol} \mathrm{dm}^{-3} \mathrm{KI}$ solution prepared in $2 \mathrm{~mol} \mathrm{dm}^{-3} \mathrm{HCl}$. Gold, palladium and platinum were quantitatively $(\geq 95 \%)$ recovered. The improvement on the recovery of platinum using KI might be due to a salting-out and synergistic effects that are very well known in solvent extraction. ${ }^{30}$

\section{Effect of sample volume}

Especially, the sample volume is important to obtain a highpreconcentration factor for the analysis of liquid samples containing analytes at very low concentration levels. Due to this, the effect of changes in the volume of the sample solution on the recoveries of gold, palladium and platinum was investigated by using test solutions prepared with $0.5 \mathrm{~mol} \mathrm{dm}^{-3}$ $\mathrm{KI}$ in a $2 \mathrm{~mol} \mathrm{dm}^{-3} \mathrm{HCl}$ solution. The test solutions contained 5 $\mu \mathrm{g}$ of gold(III), $5 \mu \mathrm{g}$ of palladium(II) and $10 \mu \mathrm{g}$ of platinum(II) per $25 \mathrm{~mL}$. As can be seen in Fig. 3, the recoveries for palladium and gold were quantitative up to sample volumes of $300 \mathrm{~mL}$ and $400 \mathrm{~mL}$, respectively. Platinum was completely recovered up to a sample volume of only $100 \mathrm{~mL}$.

\section{Influences of the sample and eluent flow rates}

It is known from previous studies that acetone is the most suitable eluent for the elution of analyte ions retained using inorganic and organic ligands on the Ambertite XAD resins. ${ }^{21,32}$ Therefore, acetone was chosen as an eluent. The minimum volume of acetone required for the quantitative elution of the retained complexes was experimentally found to be $8-9 \mathrm{~mL}$. 


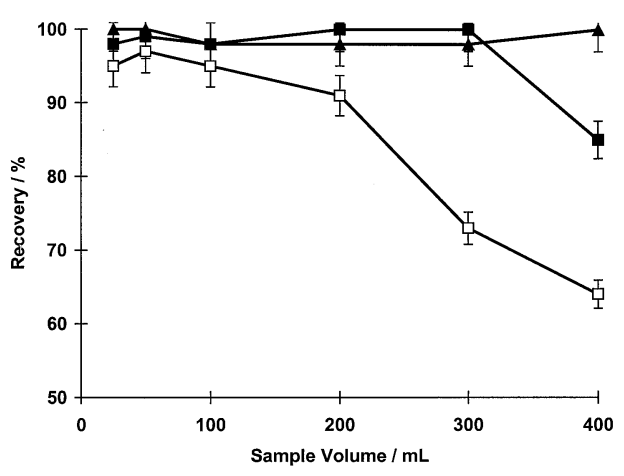

Fig. 3 Influences of the sample volume on the recoveries of gold $(\boldsymbol{\Delta})$, palladium ( $\boldsymbol{\square})$ and platinum $(\square)(n=4)$.

The sample and eluent flow rates are important parameters to obtain quantitative retention and elution, respectively. The effect of a variation in the flow rate of the sample solution on the resulting uptake of gold, palladium and platinum from 0.5 mol dm${ }^{-3} \mathrm{KI}$ in $2 \mathrm{~mol} \mathrm{dm}-3 \mathrm{HCl}$ solutions was investigated. The results are given in Table 1 . The sample flow rate range investigated for analytes was between 1.0 and $25.0 \mathrm{~mL} \mathrm{~min}{ }^{-1}$. The maximum flow rates for quantitative retentions of gold, palladium and platinum were found to be 25,11 and $4 \mathrm{~mL}$ $\mathrm{min}^{-1}$, respectively.

The effect of the eluent flow rate on the recoveries of the analyte ion was also examined. The results given in Table 2 show that varying the elution flow rate using acetone as an eluent within the range of 1.0 to $15.0 \mathrm{~mL} \mathrm{~min}^{-1}$ for gold and palladium did not significantly influence the quantitative recoveries of the analytes. For platinum, the recovery values were not quantitative after using $1.0 \mathrm{~mL} \mathrm{~min}^{-1}$ for the eluent flow rate. In further work, the flow rate of acetone was chosen to be $2.0 \mathrm{~mL} \mathrm{~min}^{-1}$ for gold and palladium.

\section{Effect of divers ions}

In order to study the effect of foreign ions on the determinations of gold, palladium and platinum with the proposed procedure, fixed amounts of the analytes, $5 \mu \mathrm{g}$ of gold(III), $5 \mu \mathrm{g}$ of palladium(II) and $10 \mu \mathrm{g}$ of platinum(II) per 25 $\mathrm{mL}$, were taken with various amounts of divers ions and the procedure was followed. The results are tabulated in Table 3. As can be seen from Table 3, platinum is considerably influenced by the divers ions. Gold and palladium is almost free from interference of the investigated divers ions until the indicated amounts.

\section{Analytical characteristics}

The analytical performance of the proposed procedure can be shown for the results of FAAS measurements. The relative standard deviations (RSD) were found in the range of 1.6 and $8.9 \%$. The recoveries obtained for gold and palladium with the model solutions in doubly distilled water were higher than $95 \%$, thus confirming the accuracy of the procedure. However, the accuracy of the proposed procedure was tested by the analysis of a sample spiked with the analyte. The analytes recovered quantitatively $(\geq 95 \%)$ from the spiked samples were determined. For this reason, the relative errors were 5\% or lower.

The detection limits $(3 s, n=20)$, based on three-times the standard deviation of the blank for gold, palladium and platinum, were found to be $32.0,24.9$ and $102.5 \mu \mathrm{g} \mathrm{L}^{-1}$, respectively. The detection limit (DL) and sensitivity limit can
Table 1 Effects of the flow rate of a sample on the retention of analyte ions (sample volume, $25 \mathrm{~mL}$ )

\begin{tabular}{crcc}
\hline \multirow{2}{*}{$\begin{array}{c}\text { Flow rate/ } \\
\mathrm{mL} \mathrm{min}^{-1}\end{array}$} & \multicolumn{3}{c}{ Recovery, $\%^{\mathrm{a}}$} \\
\cline { 2 - 4 } & \multicolumn{1}{c}{ Gold } & Palladium & Platinum \\
\hline 1.0 & $100 \pm 2$ & $108 \pm 2$ & $95 \pm 3$ \\
4.0 & $105 \pm 3$ & $100 \pm 2$ & $95 \pm 1$ \\
11.0 & $105 \pm 1$ & $95 \pm 3$ & $81 \pm 2$ \\
15.0 & $98 \pm 2$ & $69 \pm 2$ & $71 \pm 2$ \\
25.0 & $103 \pm 2$ & $69 \pm 3$ & $71 \pm 1$ \\
\hline
\end{tabular}

a. Mean $\pm \operatorname{SD}(n=3)$.

Table 2 Influences of the eluent flow rate on the recovery of gold, palladium and platinum (sample volume; $25 \mathrm{~mL}$ )

\begin{tabular}{cccc}
\hline \multirow{2}{*}{$\begin{array}{c}\text { Flow rate/ } \\
\mathrm{mL} \mathrm{min}^{-1}\end{array}$} & Gold & Palladium & Platinum \\
\cline { 2 - 4 } & $101 \pm 2$ & $96 \pm 1$ & $95 \pm 1$ \\
1.0 & $106 \pm 2$ & $95 \pm 2$ & $92 \pm 2$ \\
2.0 & $102 \pm 2$ & $99 \pm 3$ & $80 \pm 1$ \\
4.0 & $102 \pm 3$ & $93 \pm 2$ & $80 \pm 2$ \\
9.0 & $101 \pm 2$ & $98 \pm 2$ & $70 \pm 2$ \\
15.0 & & & \\
\hline
\end{tabular}

a. Mean $\pm \operatorname{SD}(n=3)$.

Table 3 Effects of diverse ions on the recovery of analytes from a $25 \mathrm{~mL}$ of a sample solution

\begin{tabular}{|c|c|c|c|c|c|}
\hline \multirow{2}{*}{$\begin{array}{l}\text { Divers } \\
\text { ions }\end{array}$} & \multicolumn{2}{|c|}{$\begin{array}{l}\text { Amount of divers } \\
\text { ions } / \mu \mathrm{g}\end{array}$} & \multicolumn{3}{|c|}{ Recovery, $\%^{\mathrm{a}}$} \\
\hline & $\begin{array}{l}\text { In the } \\
\text { sample }\end{array}$ & $\begin{array}{l}\text { In the } \\
\text { effluent }\end{array}$ & Gold & Palladium & Platinum \\
\hline \multirow[t]{3}{*}{$\mathrm{Cu}^{2+}$} & 1250 & 3.5 & $102 \pm 2$ & $93 \pm 2$ & $72 \pm 2$ \\
\hline & 2500 & 4.7 & $102 \pm 2$ & $93 \pm 2$ & $80 \pm 2$ \\
\hline & 6250 & 17.8 & $107 \pm 2$ & $94 \pm 3$ & $78 \pm 2$ \\
\hline \multirow[t]{2}{*}{$\mathrm{Fe}^{2+}$} & 2500 & 10.5 & $97 \pm 1$ & $92 \pm 1$ & $69 \pm 1$ \\
\hline & 6250 & 6.3 & $105 \pm 2$ & $95 \pm 2$ & $72 \pm 2$ \\
\hline \multirow[t]{2}{*}{$\mathrm{Ni}^{2+}$} & 1250 & 6.0 & $105 \pm 1$ & $107 \pm 2$ & $70 \pm 1$ \\
\hline & 6250 & 65.9 & $100 \pm 2$ & $57 \pm 1$ & $89 \pm 1$ \\
\hline \multirow[t]{2}{*}{$\mathrm{Ca}^{2+}$} & 1250 & 10.6 & $108 \pm 2$ & $100 \pm 2$ & $80 \pm 2$ \\
\hline & 6250 & 18.1 & $100 \pm 2$ & $94 \pm 3$ & $75 \pm 2$ \\
\hline \multirow[t]{2}{*}{$\mathrm{Pb}^{2+}$} & 1250 & 59.6 & $98 \pm 1$ & $91 \pm 3$ & $60 \pm 2$ \\
\hline & 6250 & 226.8 & $90 \pm 1$ & $94 \pm 2$ & $77 \pm 2$ \\
\hline $\mathrm{Mg}^{2+}$ & 6250 & 41.4 & $105 \pm 2$ & $96 \pm 2$ & $90 \pm 2$ \\
\hline $\mathrm{Cr}^{3+}$ & 6250 & 4.5 & $95 \pm 1$ & $96 \pm 2$ & $100 \pm 2$ \\
\hline $\mathrm{Zn}^{2+}$ & 6250 & $<0.1$ & $98 \pm 3$ & $98 \pm 3$ & $48 \pm 1$ \\
\hline $\mathrm{Na}^{+}$ & 6250 & $<0.1$ & $102 \pm 2$ & $96 \pm 2$ & $94 \pm 2$ \\
\hline $\mathrm{As}^{3+}$ & 6250 & 34.5 & $91 \pm 2$ & $102 \pm 2$ & $100 \pm 1$ \\
\hline $\mathrm{Sb}^{3+}$ & 6250 & 11.9 & $95 \pm 2$ & $94 \pm 2$ & $89 \pm 2$ \\
\hline
\end{tabular}

a. Mean $\pm \operatorname{SD}(n=4)$.

be decreased by one order of magnitude by increasing the sample volume.

\section{Analysis of pure copper and anodic slime}

The proposed procedure was applied to determine gold, palladium and platinum in a pure copper sample. Firstly, recovery experiments were carried out with a spiked copper solution prepared with $50 \mathrm{mg}$ of pure copper, because a certified reference material was not available. The results are given in Table 4. The content of gold for the copper sample was found 
Table 4 Recoveries of spiked gold, palladium and platinum in a pure copper solution (sample volume, $50 \mathrm{~mL}$ )

\begin{tabular}{lccc}
\hline Analyte & Added $/ \mu \mathrm{g}$ & Found $^{\mathrm{a}} / \mu \mathrm{g}$ & Recovery, \% \\
\hline Gold & 0 & $0.30 \pm 0.02$ & - \\
& 10.0 & $10.5 \pm 0.3$ & 102 \\
Palladium & 20.0 & $20.2 \pm 0.8$ & 100 \\
& 0 & $<\mathrm{DL}^{\mathrm{b}}$ & - \\
\multirow{4}{*}{ Platinum } & 10.0 & $9.6 \pm 0.7$ & 96 \\
& 20.0 & $18.0 \pm 0.3$ & 90 \\
& 0 & $<\mathrm{DL}$ & - \\
& 10.0 & $5.1 \pm 0.3$ & 51 \\
\hline
\end{tabular}

a. Mean $\pm \operatorname{SD}(n=3)$.

b. Detection limit.

Table 5 Recoveries of spiked gold and palladium from an anodic slime solution (sample, H1; sample amount, $100 \mathrm{mg}$ )

\begin{tabular}{lccc}
\hline Analyte & Added $/ \mu \mathrm{g}$ & Found $^{\mathrm{a}} / \mu \mathrm{g}$ & Recovery, $\%$ \\
\hline Gold & 0 & $39.65 \pm 0.52$ & - \\
& 10.0 & $49.62 \pm 0.36$ & 100 \\
Palladium & 20.0 & $58.26 \pm 0.13$ & 93 \\
& 0 & $<\mathrm{DL}^{\mathrm{b}}$ & - \\
& 10.0 & $0.43 \pm 0.01$ & 4 \\
& 20.0 & $0.38 \pm 0.02$ & 2 \\
\hline
\end{tabular}

a. Mean $\pm \operatorname{SD}(n=6)$.

b. Detection limit.

Table 6 Content of gold in anodic slime samples $(n=6 ; 95 \%$ C.L.)

\begin{tabular}{ccc}
\hline Sample amount/mg & Concentration of gold $/ \mu \mathrm{g} \mathrm{g}^{-1}$ & $\mathrm{RSD}$ \\
\hline 100 & $386 \pm 23$ & 0.06 \\
200 & $384 \pm 22$ & 0.06 \\
\hline
\end{tabular}

a. $x \pm t . s / \sqrt{n}$, with confidence limit at $95 \%$ confidence level $(s$ : standard deviation).

to be $6.0 \pm 0.3 \mu \mathrm{g} \mathrm{g}^{-1}$ ( $n=6$ at the $95 \%$ confidence level). RSD was calculated to be $5.1 \%$. Palladium was not detected using the proposed procedure. As expected, the recovery of platinum, influenced by copper ions as divers ions, was low.

The procedure was applied to anodic slime samples having a more complex matrix than pure copper. ${ }^{12}$ The correctness of the results was tested by an analysis of spiked anodic slime samples. As can be seen from Table 5, because of the complex matrix, palladium was not recovered from the slime sample. Also, the recovery of platinum was influenced by anodic slime including copper at a high concentration. In contrast to platinum and palladium, gold in the slime samples could be accurately determined by the proposed procedure, as can be seen from Table 5. For this reason, the gold content of an anodic slime sample, obtained from the electrolysis of blister copper, was determined (Table 6).

In conclusion, the proposed procedure provides a simple, fairly rapid and reliable technique for the preconcentration and determination of gold from some metallurgical sample having a complex matrix, such as pure copper and anodic slime. However, the procedure can be applicable to a palladium determination only under some limited conditions. The determination of platinum in several real samples is impossible with the proposed procedure.

\section{References}

1. D. A. Chowdhury and S. Kamata, Chem. Lett., 1994, 3, 589.

2. S. Terashima and M. Taniguchi, Bunseki Kagaku, 1999, 48, 847.

3. K. Saito, I. Taninaka, Y. Yamamoto, S. Murakami, and A. Muromatsu, Talanta, 2000, 51, 913.

4. S. Arpadjan, L. Jordanova, and I. Karadjova, Fresenius J. Anal. Chem., 1993, 347, 480.

5. K. Oguri, G. Shimoda, and Y. Tatsumi, Chem. Geol., 1999, $157,189$.

6. K. Akatsuka, S. Hoshi, T. Katoh, S. N. Willie, and J. W. Mclaren, Chem. Lett., 1995, 9, 817.

7. H. Minamisawa, Y. Tatehaba, N. Arai, and T. Okutani, Anal. Sci., 1996, 12, 947.

8. I. Matsubara, Y. Takeda, and K. Ishida, Fresenius. J. Anal. Chem., 2000, 366, 213.

9. L. Elci, Anal. Lett., 1993, 26, 1025.

10. Z. X. Su, Q. S. Pu, X. Y. Luo, X. J. Chang, G. Y. Zhan, and F. Z. Ren, Talanta, 1995, 42, 1127.

11. I. A. Kovalev, L. V. Bogacheva, G. I. Tsysin, A. A. Formanovsky, and Y. A. Zolotov, Talanta, 2000, 52, 39.

12. L. Elci, S. Isildar, and M. Dogan, Anal. Chim. Acta, 1994, 293, 319.

13. A. Tunceli and A. R. Turker, Anal. Sci., 2000, 16, 81.

14. R. D. Oleschuk and A. Chow, Talanta, 1998, 45, 1235.

15. A. Uzawa, W. Yoshimura, and T. Okutani, Bunseki Kagaku, 1995, 44, 391.

16. S. L. Lin, C. S. Zheng, and G. H. Yun, Talanta, 1995, 42, 921.

17. M. Soylak, L. Elci, and M. Dogan, Anal. Lett., 2000, 33, 513.

18. P. Liu, Q. S. Pu, and Z. X. Su, Analyst, 1999, 125, 147.

19. P. Liu, Q. S. Pu, Q. Y. Sun, and Z. X. Su, Fresenius J. Anal. Chem., 2000, 366, 816.

20. L. Elci, M. Soylak, and M. Dogan, Fresenius J Anal. Chem., 1992, 342, 175.

21. M. Soylak, L. Elci, and M. Dogan, Fresenius J Anal. Chem., 1995, 351, 308.

22. M. Soylak, L. Elci, and M. Dogan, Anal. Lett., 1997, 30, 623.

23. M. Soylak, L. Elci, and M. Dogan, J. Trace Microprobe Tech., 1999, 17, 149.

24. L. Elci, M. Soylak, A. Uzun, E. Buyukpatir, and M. Dogan, Fresenius J. Anal. Chem., 2000, 368, 358.

25. H. Minamisawa, N. Arai, Y. Tatehaba, and T. Okutani, Nippon Kagaku Kaishi, 1995, 7, 512.

26. A. Tunceli and A. Turker, Analyst, 1997, 122, 239.

27. A. G. Sillen and A. E. Martell, "Stability Constants of Metal-Ion Complexes", 1964, The Chemical Society, London, 283 - 285, 322 - 324, 338.

28. M. Marczenko, "Separation and Spectrophotometric Determination of Elements", 1986, Wiley, Chichester, 298 - 306, 437 - 446, 457 - 465.

29. M. Mojski, Talanta, 1978, 25, 163.

30. J. Minczewski, D. Chwastowska, and R. Dybezynski, "Separation and Preconcentration Methods in Inorganic Trace Analysis", 1982, Ellis Horwood, New York, 135 145, 168 - 171, 235 - 236.

31. K. S. Patel and K. H. Lieser, Anal. Chem., 1986, $58,1547$.

32. M. Soylak, U. Sahin, and L. Elci, Anal. Chim. Acta, 1996, $322,111$. 